\title{
Removal of sialic acid from bull sperm decreases motility and mucus penetration ability but increases zona pellucida binding and polyspermic penetration in vitro
}

\author{
B Fernandez-Fuertes ${ }^{1}$, A Blanco-Fernandez ${ }^{2}$, C J Reid ${ }^{3}$, K G Meade ${ }^{4}$, S Fair ${ }^{5}$ and P Lonergan ${ }^{1}$ \\ ${ }^{1}$ School of Agriculture and Food Science, University College Dublin, Dublin, Ireland, ${ }^{2}$ Flow Cytometry Core \\ Facilities, UCD-Conway Institute of Biomolecular and Biomedical Research, University College Dublin, Dublin, \\ Ireland, ${ }^{3}$ School of Veterinary Medicine, Veterinary Sciences Centre, University College Dublin, Dublin, Ireland, \\ ${ }^{4}$ Animal \& Grassland Research and Innovation Centre, Teagasc, Grange, County Meath, Ireland and ${ }^{5}$ Department of \\ Biological Sciences, Laboratory of Animal Reproduction, Faculty of Science and Engineering, University of Limerick, \\ Limerick, Ireland
}

Correspondence should be addressed to P Lonergan; Email: pat.lonergan@ucd.ie

\begin{abstract}
This study tested the hypothesis that sperm sialic acid (Sia) is required to reach the site of fertilization, and that successful fertilization requires recognition of Sia from both the sperm and oocyte to occur. In addition, it has recently been reported that Siglecs (Sia-binding-immunoglobulin-like lectins) are present on the sperm surface. Thus, the possibility that the recognition of oocyte Sia was sperm-Siglec-mediated was also addressed. Sperm exposed to neuraminidase (NMase) exhibited lower overall and progressive motility, which translated to a decreased ability to swim through cervical mucus from cows in oestrus. In addition, when either sperm or cumulus-oocyte complexes (COCs) were treated with NMase, a decrease in cleavage and blastocyst rate was observed. However, incubation of sperm with increasing concentrations of anti-Siglec-2, -5, -6 and -10 antibodies prior to fertilization had no effect on their fertilizing ability. Interestingly, treatment with NMase increased the number of sperm bound to the ZP but also the rate of polyspermic fertilization. Flow cytometry analysis revealed no differences in the percentage of capacitated or acrosome-reacted sperm. These results suggest that Sia are required to reach the site of fertilization but need to be removed for sperm-oocyte interaction. However, fine regulation is needed to avoid abnormal fertilization which can lead to impaired embryo development. Reproduction (2018) 155 481-492
\end{abstract}

\section{Introduction}

Sperm are coated with a thick $(20-60 \mathrm{~nm})$ glycocalyx composed of different glycolipids, glycoproteins and glycosylphosphatidylinositol (GPI)-anchored proteins (Tecle \& Gagneux 2015). The oocyte is also surrounded by a heavily glycosylated matrix, the zona pellucida (ZP). Thus, glycoconjugates from both the male and female reproductive tracts are critical components of the molecular mechanisms underlying the control of the interaction between both gametes and with the female reproductive tract and its secretions. In mammals, the terminal monosaccharides of glycans are often small, negatively charged monosaccharides called sialic acids (Sia) (Tecle \& Gagneux 2015). This privileged location means that Sia can potentially interact with the extracellular milieu and neighbouring cells to elicit different responses at an intracellular level.

Although all cell surfaces contain numerous Sia, the sperm sialome is especially abundant in comparison with somatic cells (Kraemer 1966, Tecle \& Gagneux
2015). This sperm sialome is established during spermatogenesis, epididymal maturation and by incorporation of sialylated seminal fluid components during ejaculation (Ma et al. 2016). In the epididymis, acquisition of the sperm sialome occurs in a regiondependent matter. For example, in mouse testicular sperm, only Sia $\alpha 2-3$ is present, whereas Neu5Ac, which comprises more than $20 \%$ of mature mouse sperm Sia, is transferred by sialyltransferase in the caput and corpus epididymis (Ma et al. 2016). The abundant sialylation found on the sperm surface highlights the importance of these sugars in sperm function. Sia have been found to mediate numerous and diverse biological roles in different cell types through their ability to act as both recognition sites for a variety of molecules such as hormones, lectins, antibodies or inorganic cations, or masking receptors located on the cell surface (Varki \& Schauer 2009). In sperm, Sia likely facilitates tolerance by female innate pattern-recognition molecules, and may play a role in masking potential antigenic sperm molecules until after sperm have undergone capacitation 
(Toshimori et al. 1988, 1991, Yudin et al. 2005). In addition to this immunological role, the relatively strong electronegative charge of Sia has been linked to an enhanced ability of sperm to travel through the mucuslined female tract in macaques (Tollner et al. 2008a). In fact, reduction of Sia content in human sperm has been correlated with subfertility due to the inability of these cells to migrate through the mucus matrix in the reproductive tract (Tollner et al. 2011).

Apart from masking receptors, sperm surface Sia are potentially able to interact with Siglecs (sialic acidbinding-immunoglobulin-like lectins) on the female reproductive tract. Siglecs are transmembrane receptors that have distinct preferences for binding the diverse types of sialylated glycans present on cell surfaces (Macauley et al. 2014). These proteins have been shown to play a role as regulators of immune cell function. Binding of Siglecs to leukocyte Sia downregulates the immune response of the cell (Crocker et al. 2007). In mice, sperm have been found to strongly bind to Siglec-6, which is predominantly expressed by B cells (Ma et al. 2012). This may be the mechanism behind the lower phagocytosis rate observed when epididymal mouse sperm are coated with Sia (Ma et al. 2016), or the reason why removal of the highly sialylated $\beta$-defensin 126 or treatment with neuraminidase elicits female immunorecognition (Yudin et al. 2005). Interestingly, proteomic and transcriptional studies have identified several Siglecs in both human and bovine sperm (Lalancette et al. 2008, Peddinti et al. 2008, Amaral et al. 2014). In the bovine, Siglec-2, -5, -6 and -10 have been found to be preferentially expressed in the neck region and, in the case of Siglec- 6 and -10 , the anterior head of sperm (Alkhodair et al. 2018). The role of these molecules in sperm has not been elucidated to date. However, it is interesting to note that Siglec-10 was found to be differentially expressed in sperm from bulls with a high fertility index (Lalancette et al. 2008). Sperm-ZP binding has been shown to be Sia-mediated in both humans and cattle (Velásquez et al. 2007, Pang et al. 2011). In the cow, 85\% of ZP glycoproteins contain Neu5Ac moieties (Velásquez et al. 2007). In this species, interaction of an unknown sperm ligand with $\alpha$-2,3-linked Sia is required for ZP binding (Velásquez et al. 2007).

Based on this information, it seems that Sia are required for sperm to reach the site of fertilization, but removal of part of the sperm sialome is required to enable interaction with the ZP. Interestingly, $80 \%$ of the sperm Sia remain intact after capacitation (Ma et al. 2012). These remaining Sia could potentially interact with the oocyte vestments in order to facilitate successful fertilization. Therefore, the aim of this study was to determine how removal of bovine sperm Sia affects sperm ability to reach the site of fertilization, undergo capacitation and fertilize oocytes in vitro. In addition, we also tested the hypothesis that interaction with oocyte Sia occurs through sperm surface Siglecs.

\section{Materials and methods}

All chemicals and reagents were purchased from SigmaAldrich Chemical unless stated otherwise.

The frozen semen straws from one bull that were used in the different experiments were obtained from the National Cattle Breeding Centre (Naas, Ireland). Straws obtained from the same ejaculate of the same bull were used to carry out all experiments described in the following section.

\section{Experiment 1: Effect of neuraminidase treatment on sperm ability to migrate through cervical mucus}

The aim of Experiment 1 was to determine how treatment of sperm with $C$. perfringens type $\mathrm{V}$ Neuraminidase (NMase), a sialidase that cleaves sialic acid, would affect their ability to penetrate oestrus cervical mucus (CM).

\section{Assessment of Sia loss from the sperm membrane}

In order to determine the degree of sialic acid loss that occurs in the presence or absence of NMase under the conditions of this study, sperm were labelled with lectin from Triticum vulgaris (wheat germ agglutinin - WGA) which binds to Sia (Monsigny et al. 1980).

Sperm incubated in the presence or absence of NMase for $1 \mathrm{~h}$ or $5 \mathrm{~h}$ were air-dried on top of slides and then fixed in $4 \%$ paraformaldehyde/PBS for $45 \mathrm{~min}$. Sperm were subsequently blocked with blocking buffer (4\% BSA/PBS) for $1 \mathrm{~h}$, and then incubated with biotinylated WGA $(1 \mu \mathrm{g} / \mathrm{mL})$ for an additional hour. After three washes in PBS, sperm were incubated for $1 \mathrm{~h}$ Alexa Fluor 488-streptavidin conjugate (1:500; Life Technologies). Finally, samples were washed three additional times in PBS and incubated with Hoechst 33342 for 10 min. The slides were mounted with Mowiol, and sperm were then observed under a Leica DMI6000B epifluorescence microscope equipped with a $40 \times$ oil immersion objective.

The percentage of positively stained sperm, negative sperm (no stain visible) and partially stained sperm were assessed for each treatment group. Two setups were carried out with at least 50 cells assessed per set up and treatment.

\section{Cervical mucus penetration}

CM was collected from cows observed in standing oestrus. A polyethylene catheter attached to a 20-mL syringe was inserted into the vagina and guided towards the external cervical os. Once the catheter was in position, gentle suction was applied to recover the CM. Mucus from three different cows was pooled, aliquoted and stored at $-20^{\circ} \mathrm{C}$. CM from the same pool was used throughout and the mucus penetration test was carried out as described by Kiernan et al. (2013). Motile, frozen-thawed, bull sperm were selected by washing through a $90-45 \%$ Percoll gradient. This was followed by a second wash in HEPES-buffered Tyrode medium and the assessment of sperm concentration with the use of a hemocytometer. Sperm were diluted to achieve a concentration of $20 \times 10^{6} \mathrm{sperm} / \mathrm{mL}$, and separated into two groups. One group was incubated with $0.1 \mathrm{UN} / \mathrm{mL}$ NMase, while the other group received an equivalent volume of HEPES-buffered Tyrode medium for $1 \mathrm{~h}$ 
or $5 \mathrm{~h}$. Flattened capillary tubes $(0.3 \mathrm{~mm} \times 3.0 \mathrm{~mm} \times 100 \mathrm{~mm}$; Composite Metal Services Ltd., Shipley, UK) were marked at 10-mm intervals between 10 and $90 \mathrm{~mm}$, filled with thawed mucus and put in an incubator at $38.5^{\circ} \mathrm{C}$ while sperm were processed. At $1 \mathrm{~h}$ or $5 \mathrm{~h}$, a $250-\mu \mathrm{L}$ sample from each treatment was stained with Hoechst $33342(10 \mu \mathrm{g} / \mathrm{mL})$ for $10 \mathrm{~min}$ at $38.5^{\circ} \mathrm{C}$. Following staining, two mucus-filled capillaries were placed vertically into an Eppendorf tube containing the stained sperm dilution and left for $30 \mathrm{~min}$ in an incubator at $39^{\circ} \mathrm{C}$ under an atmosphere of $5 \% \mathrm{CO}_{2}$ in air with maximum humidity. Capillary tubes were then removed and placed on a hot plate at $70^{\circ} \mathrm{C}$ for $3 \mathrm{~min}$ to immobilize the sperm. Sperm were counted across the width of the tube, one field of view wide under $40 \times$ magnification, at each $10-\mathrm{mm}$ interval between 10 and $90 \mathrm{~mm}$ using a fluorescent microscope (Nikon Eclipse TE2000s). Four replicates were completed with two capillary tubes representing each treatment in each replicate.

\section{Experiment 2: Effect of neuraminidase treatment of sperm or oocytes in in vitro fertilization}

The aim of Experiment 2 was to determine how treatment of sperm or oocytes with $C$. perfringens type $\mathrm{V}$ Neuraminidase (NMase) would affect the outcome of in vitro fertilization.

\section{In vitro fertilization}

Ovaries from cows and heifers were collected at a commercial abattoir, and surface-visible follicles $(>2 \mathrm{~mm}$ ) were aspirated to recover cumulus-oocyte complexes (COCs). Good-quality COCs were matured in TCM-199 supplemented with $10 \%(\mathrm{v} / \mathrm{v})$ foetal calf serum (FCS) and $10 \mathrm{ng} / \mathrm{mL}$ epidermal growth factor $\left(n=50\right.$ COCs per well) for $24 \mathrm{~h}$ at $39^{\circ} \mathrm{C}$ under an atmosphere of $5 \% \mathrm{CO}_{2}$ in air with maximum humidity. After maturation, sperm were processed and treated with NMase for $1 \mathrm{~h}$ as described earlier. Matured COCs were randomly divided into two equal groups, one incubated in the presence of $0.1 \mathrm{UN}$ / $\mathrm{mL}$ NMase and a control group. After $1 \mathrm{~h}$ of incubation, sperm were washed twice by centrifugation in HEPES-buffered Tyrode medium at $500 \mathrm{~g}$ for $5 \mathrm{~min}$, and concentration was adjusted to $2 \times 10^{6} \mathrm{sperm} / \mathrm{mL}$ in fertilization media containing $113.16 \mathrm{mM}$ $\mathrm{NaCl}, 3.19 \mathrm{mM} \mathrm{KCl}, 0.2 \mathrm{mM} \mathrm{NaH}{ }_{2} \mathrm{PO}_{4}, 2 \mathrm{mMCaCl}, 0.487 \mathrm{mM}$ $\mathrm{MgCl}_{2}, 0.5 \mathrm{mM}$ pyruvate, $12.79 \mathrm{mM} \mathrm{NaHCO}{ }_{3}^{-}, 6 \mathrm{mg} / \mathrm{mL} \mathrm{BSA}$ and $10 \mu \mathrm{g} / \mathrm{mL}$ heparin ( $\mathrm{pH}:$ 7.4). COCs were also washed three times in the same medium. Groups of 50 matured COCs were randomly allocated to the following experimental treatments: (i) NMase COCs (COCs incubated with NMase and fertilized with untreated sperm; $n=127$ COCs), (ii) NMase sperm (COCs fertilized with sperm incubated with NMase; $n=124$ COCs) or (iii) control (untreated COCs, fertilized with untreated sperm; $n=144$ COCs). Three replicates were carried out and each treatment was equally represented in each replicate. Approximately $20 \mathrm{~h}$ post fertilization, cumulus cells were removed from presumptive zygotes and washed in PBS before being transferred in groups of 25 to culture drops of synthetic oviduct fluid supplemented with 5\% FCS. Culture dishes were kept at $39^{\circ} \mathrm{C}$ under an atmosphere of $5 \% \mathrm{CO}_{2}$ and $5 \% \mathrm{O}_{2}$ in air with maximum humidity. Cleavage was assessed $48 \mathrm{~h}$ post fertilization and blastocyst development was recorded on
Day 8 (Day 0 = day of fertilization) and expressed over the total number of oocytes fertilized.

To determine if increasing the duration of incubation with NMase could have a more dramatic effect due to more Sia being removed, COCs were fertilized with the following sperm treatments: (i) sperm NMase $1 \mathrm{~h}$ (sperm incubated with NMase for $1 \mathrm{~h}, n=172 \mathrm{COCs}$ ), (ii) control $1 \mathrm{~h}$ (sperm incubated for $1 \mathrm{~h}$ in an equivalent volume of HEPES-buffered Tyrodes, $n=193$ COCs), (iii) sperm NMase $5 \mathrm{~h}$ (sperm incubated in the presence of NMase for $5 \mathrm{~h}, n=192$ COCs) and (iv) control $5 \mathrm{~h}$ (sperm incubated for $5 \mathrm{~h}$ in an equivalent volume of HEPES-buffered Tyrodes, $n=181$ COCs). Alternatively, COCs were incubated with or without (control) NMase for 1 or $5 \mathrm{~h}$ (COCs NMase $1 \mathrm{~h}, n=118$ COCs; control $1 \mathrm{~h}, n=129$ COCs; COCs NMase $5 \mathrm{~h}, n=133 \mathrm{COCs}$; control $5 \mathrm{~h}, n=121 \mathrm{COCs})$, and fertilized with untreated sperm. In both cases, $20 \mathrm{~h}$ post fertilization, presumptive zygotes were cultured and cleavage and blastocyst development were assessed as described earlier.

\section{Assessment of sperm-ZP binding and penetration}

To further explore the effect of sperm NMase treatment on sperm-oocyte interaction, the ability of treated sperm to bind to the ZP and penetrate the oocyte plasma membrane was studied. In vitro maturation was performed as previously described. After maturation, COCs were divided into two groups. One group was stripped free of cumulus cells by gentle pipetting in PBS and placed in fertilization media. The second group was placed in fertilization media without removing their cumulus cells. Percoll-selected motile sperm were incubated for $5 \mathrm{~h}$ in the presence of NMase or an equivalent volume of HEPES-buffered Tyrodes. They were then washed, as described earlier and used to fertilize both denuded and cumulus-intact oocytes. Sperm and oocytes were coincubated in an incubator with $5 \% \mathrm{CO}_{2}, 38.5^{\circ} \mathrm{C}$ and maximum humidity. Three hours after incubation, cumulus-free oocytes were vortexed for $30 \mathrm{~s}$ to remove sperm not tightly bound to the ZP. They were then fixed in $4 \%$ paraformaldehyde/PBS for $45 \mathrm{~min}$, washed three times in PBS and mounted on a slide with Mowiol mounting medium and stained with Hoechst $33342(10 \mu \mathrm{g} / \mathrm{mL})$. Oocytes were then observed with a fluorescent microscope (Olympus BX60) at 40× magnification and the number of sperm bound to their ZP was recorded. Cumulus-intact oocytes were stripped from the cumulus cells $17 \mathrm{~h}$ post fertilization by gentle pipetting. They were then fixed, and mounted and viewed in the same way as the previous group. Oocytes were observed under an Olympus BX60 microscope at 40× magnification, and the presence and number of pronuclei were recorded.

\section{Experiment 3: Effect of NMase treatment on sperm motility, capacitation and the acrosome reaction}

Experiment 3 aimed to determine whether release of Sia by NMase treatment would induce motility or capacitation changes and activate the acrosome reaction.

\section{CASA analysis}

Sperm exposed to NMase for 1 or $5 \mathrm{~h}$, with the corresponding controls, were assessed for motility using a CASA system 
(IVOS II Clinical; Hamilton Thorne, IMV Technologies, L'Aigle, France). A sample from each treatment was placed on a $20-\mu \mathrm{L}$ 4-chamber Leja slide (Micro Optic, Wardenburg, Germany) and evaluated. Percentage of motile and progressively motile sperm were evaluated. In addition, the following motion parameters were also measured: curvilinear velocity (VCL, total distance travelled by the sperm head per unit of time; $\mu \mathrm{m} / \mathrm{s}$ ), velocity straight line (VSL, the straight line distance travelled by the sperm head per unit of time; $\mu \mathrm{m} / \mathrm{s}$ ), velocity average path (VAP, the average velocity of the sperm head; $\mu \mathrm{m} / \mathrm{s}$ ), linearity (LIN, straightness of trajectory, \%), amplitude of lateral head displacement $(\mathrm{ALH}$, degree of side-to-side head movement; $\mu \mathrm{m}$ ), distance average path (DAP, the average path distance of the sperm head; $\mu \mathrm{m}$ ), distance curved line (DCL, the averaged curved distance travelled by the sperm head; $\mu \mathrm{m}$ ), distance straight line (DSL, the average straight line distance travelled by the sperm head; $\mu \mathrm{m}$ ), wobble (WOB, the side-to-side movement of the sperm head measured as the ratio of velocity average path divided by the curvilinear velocity; \%) and beat cross frequency (BCF the frequency at which the sperm head moves across the middle plane of the 'straightened' trajectory, Hz). Four chambers were assessed per sample with a minimum of 100 sperm cells counted in a minimum of 8 fields of view per slide. The experiment was replicated three times.

\section{Flow cytometry}

In order to analyse sperm capacitation and acrosomal status, flow cytometric analysis was performed on sperm incubated in the presence or absence of NMase. Sperm were washed as described earlier and concentration was adjusted to $3 \times 10^{6} \mathrm{sperm} / \mathrm{mL}$. Sperm were diluted in fertilization media containing $113.16 \mathrm{mM} \mathrm{NaCl}, 3.19 \mathrm{mM} \mathrm{KCl}, 0.2 \mathrm{mM} \mathrm{NaH}_{2} \mathrm{PO}_{4}$, $2 \mathrm{mM} \mathrm{CaCl}_{2}, 0.487 \mathrm{mM} \mathrm{MgCl}_{2}, 0.5 \mathrm{mM}$ pyruvate, $12.79 \mathrm{mM}$ $\mathrm{NaHCO}_{3}{ }^{-}, 6 \mathrm{mg} / \mathrm{mL} \mathrm{BSA}$ and $10 \mu \mathrm{g} / \mathrm{mL}$ heparin, a medium that has been shown to support sperm capacitation. This medium was supplemented with $0.1 \mathrm{U} / \mathrm{mL}$ NMase, or with an equivalent volume of fertilization media (control). Both NMase and control sperm samples were split into two groups; in one, $5 \mu \mathrm{M} \mathrm{Ca}^{2+}$ ionophore was added, while in the other one, an equivalent volume of fertilization media was added. Samples were incubated in an incubator at $39^{\circ} \mathrm{C}$ under an atmosphere of $5 \% \mathrm{CO}_{2}$ and $5 \% \mathrm{O}_{2}$ in air with maximum humidity. At times 0 (T0), $1 \mathrm{~h}$ (T1), $3 \mathrm{~h}$ (T3) and $5 \mathrm{~h}$ (T5), a sample from each group was taken and $5 \mu \mathrm{M}$ merocyanine 540 (MC; Life Technologies), a reporter probe for phospholipid scrambling (Harrison et al. 1996); $1 \mu \mathrm{M}$ Yo-Pro-1 (YP; Life Technologies), a membraneimpermeable nucleic acid stain (Harrison et al. 1996); and $0.5 \mu \mathrm{g} / \mathrm{mL}$ Alexa Fluor 647-conjugated-Arachis hypogaea (peanut) agglutinin (PNA; Life Technologies), a lectin that binds to the outer acrosomal membrane (Flesch et al. 1998), were added. Samples were incubated for $10 \mathrm{~min}$ with the stains before flow cytometric analysis.

Flow cytometric analysis was performed with a standard bench-top BD Accuri C6 flow cytometer (Becton Dickinson Biosciences, Ann Arbor, MI, USA, with BD Accuri C6 software v. 1.0.264.21). The cytometer was calibrated daily according to the manufacturer's recommendations with 8 and 6 peak calibration beads. The cytometer was equipped with a 488-nm and a 633-nm laser. The 488-nm laser was used for the excitation of YP and MC, and their emission was filtered using a using a $533 \pm 30$ and a $575 \pm 25$ band pass filters, respectively. The 633-nm laser was used for the excitation of PNA $(675 \pm 25)$. Filtered emissions were detected by photomultiplier tubes. A threshold of 40,000 in the forward scatter signal was applied to remove electrical noise, and very small events and samples were collected at the default low flow rate. For each sample, 15,000 single cells were recorded. Each assay was replicated three times. Titration of the dyes was carried out, and Fluorescent Minus One controls were used for an initial gating. The gating strategy used can be followed in Supplementary Fig. 1 (see section on supplementary data given at the end of this article). Further analysis was done with FCS Express 5 Flow Plus software (De Novo Software, Glendale, CA, USA).

\section{Experiment 4: Role of sperm Siglecs in sperm-oocyte interaction}

The aim of Experiment 4 was to determine whether interaction with oocyte Sia is mediated by sperm Siglecs. A motile population of frozen-thawed sperm was selected with a Percoll gradient as described earlier. Sperm concentration was then assessed and adjusted to $20 \times 10^{6} \mathrm{sperm} / \mathrm{mL}$. A blocking assay was performed by incubating sperm for $1 \mathrm{~h}$ in the presence of $1: 20$ or $1: 50$ Siglec- $2,-5,-6,-10$ or $-5 / 14$ antibodies (Siglec-2, -6 and -10 antibodies were purchased from Santa Cruz Biotechnology; anti-Siglec-5/14, and -5 antibodies were obtained from R\&D Systems). No specific anti-Siglec-14 antibody is currently available; however, a cross-reactive antibody against both Siglec-5 and 14 exists and was used to screen for Siglec-14 and compared with Siglec-5 alone. Sperm incubated with an equivalent concentration of anti-lgG antibody was used as control. After incubation, sperm were washed twice in HEPES-buffered Tyrode medium for $5 \mathrm{~min}$ at 500 g. Sperm concentration was reassessed and adjusted to $2 \times 10^{6} \mathrm{sperm} / \mathrm{mL}$. Groups of 50 in vitro matured COCs were then fertilized with sperm from different treatments. In vitro fertilization and culture were carried out as described earlier. Cleavage and blastocyst rates were recorded. Each Siglec blocking assay was replicated three times.

\section{Statistical analysis}

Data were checked for normality of distribution and homogeneity of variance using histograms, qplots and formal statistical tests in the univariate procedure (version 9.1.3; SAS Institute, Cary, NC, USA). Data that were not normally distributed were subsequently transformed prior to analysis.

The data from IVF (cleavage rate and blastocyst rate) were subjected to arcsin transformation prior to analysis. In addition, the sperm mucus penetration data required a square root transformation to normalize the residuals, as preliminary analyses revealed that the distribution of values was positively skewed. The transformed data were used to calculate $P$ values. However, the corresponding least-squares means and S.E.M. of the non-transformed data are presented in the results for clarity. 
For all individual experiments, in vitro fertility data for the proportion of oocytes that cleaved and reached the blastocyst stage were analysed using the MIXED procedure of SAS with a model that included treatment imposed as a fixed effect and bull as a random term. Additionally, sperm mucus penetration counts along the capillary tube $(10-90 \mathrm{~mm})$ were cumulatively assessed and analysed thereafter using MIXED procedure of SAS (SAS Institute) with a model that included treatment imposed as a fixed effect and bull as a random term. Interaction terms if not statistically significant $(P<0.05)$ were subsequently excluded from the final model. Differences among means were determined by F-tests using Type III sums of squares. The PDIFF option of SAS and the Tukey test were applied to evaluate pairwise comparisons between means. The level of significance was set at $P<0.05$.

\section{Results}

\section{Experiment 1: Effect of neuraminidase treatment on sperm ability to migrate through cervical mucus}

To confirm whether NMase treatment induced a higher loss of Sia from the sperm membrane, sperm were labelled with WGA. Sperm were classified as positively stained (bright fluorescence observed on the acrosomal region; Fig. 1B.1), partial loss (dimmer, grainy looking
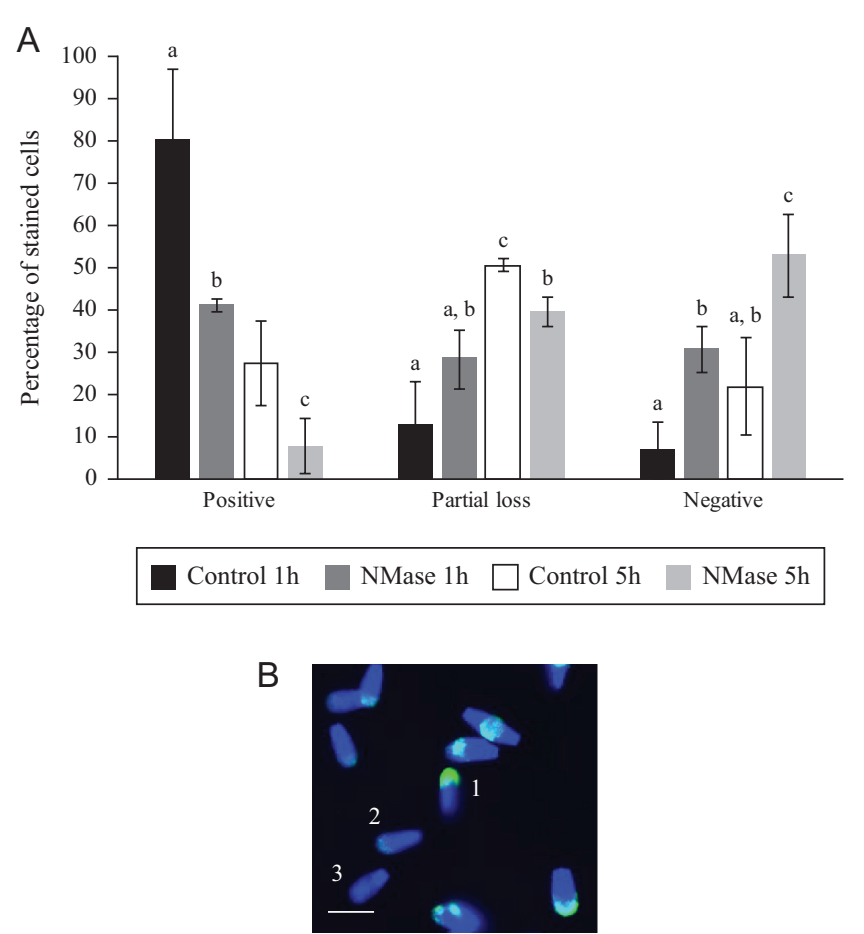

Figure 1 (A) Percentage of sperm of WGA-positive, WGA-negative or exhibiting dimmer fluorescence (partial loss of WGA labelling), after incubation for $1 \mathrm{~h}$ or $5 \mathrm{~h}$ in the presence or absence of NMase. Data reported as mean \pm S.E.M. Different superscripts between treatment groups within positive, partial loss or negative indicate a difference $(P<0.05)$. (B) Representative images of sperm classified as positive (1), partial loss of fluorescence (2) and negative (3). Bar equals $10 \mu \mathrm{m}$. Experiment 1. labelling; Fig. 1B.2) or negative (no fluorescence visible; Fig. 1B.3). Incubation of sperm for $1 \mathrm{~h}$ with this sialidase was sufficient to decrease the percentage of WGApositive sperm by half $(80 \pm 17 \%$ in the control group vs $41 \pm 2 \%$ in the NMase group; $P<0.05$; Fig. $1 \mathrm{~A})$. In both control and NMase groups, a loss of Sia was observed between $1 \mathrm{~h}$ and $5 \mathrm{~h}$ of incubation (percentage of positive cells: $80 \pm 17 \%$ at $1 \mathrm{~h}$ vs $28 \pm 10 \%$ at $5 \mathrm{~h}$ in the control group; $41 \pm 2 \%$ at $1 \mathrm{~h}$ vs $8 \pm 6 \%$ at $5 \mathrm{~h}$ in the NMase group; $P<0.05)$. However, the percentage of WGA-positive cells remained higher in the control in comparison with the NMase treatment group at $5 \mathrm{~h}$ $(28 \pm 10 \%$ in the control group vs $8 \pm 6 \%$ in the NMase group; $P<0.05)$.

Incubation of sperm for $1 \mathrm{~h}$ in the presence of NMase had no effect on the ability of sperm to migrate through CM. Fewer control sperm were observed in the capillary tube after $5 \mathrm{~h}$ of incubation in comparison with $1 \mathrm{~h}$ of incubation $(P<0.05$; Fig. 2), suggesting a timedependent decrease in mucus penetration ability. In addition, sperm incubated in the presence of NMase for $5 \mathrm{~h}$ had a reduced penetration ability in comparison with the control $(P<0.05$; Fig. 2).

\section{Experiment 2: Effect of neuraminidase treatment of sperm or oocytes in in vitro fertilization}

Treatment of COCs with NMase decreased the percentage of cleaved oocytes from $93 \pm 2 \%$ in the control group to $35 \pm 4 \% \quad(P<0.001)$. This translated into a decrease in the percentage of blastocysts from $44 \pm 4 \%$ in the control to $5 \pm 2 \%$ in the NMase-treated group $(P<0.001$; Fig. 3$)$. Although not as dramatic, the same trend was also evident when sperm were treated with NMase. Cleavage rate was reduced from $93 \pm 2 \%$ to $66 \pm 4 \%$, and the proportion of oocytes forming blastocysts at Day 8 was $27 \pm 4 \%$ vs $44 \pm 4 \%$ in the control $(P<0.001$; Fig. 3).

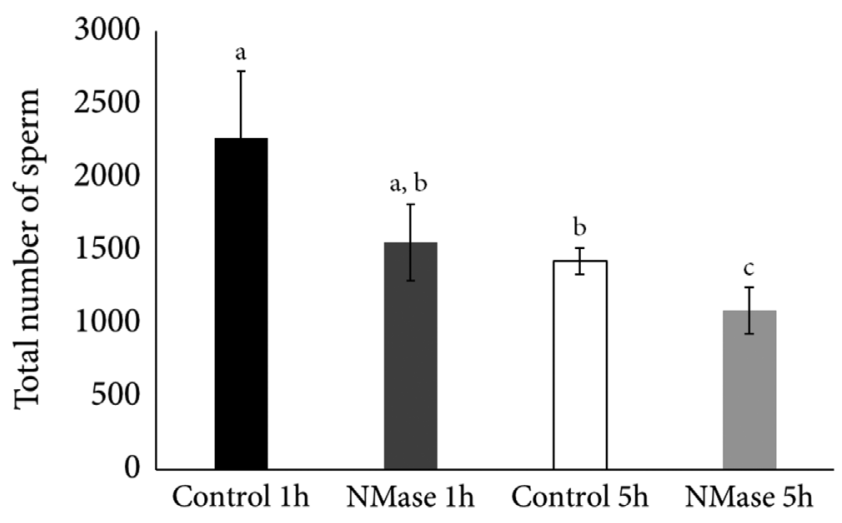

Figure 2 Total number of sperm found in the mucus-filled capillary tube after incubation for $1 \mathrm{~h}$ or $5 \mathrm{~h}$ in the presence or absence (control) of NMase. Data reported as least-squares means \pm S.E.M. Different superscripts indicate a difference $(P<0.05)$. Experiment 1. 


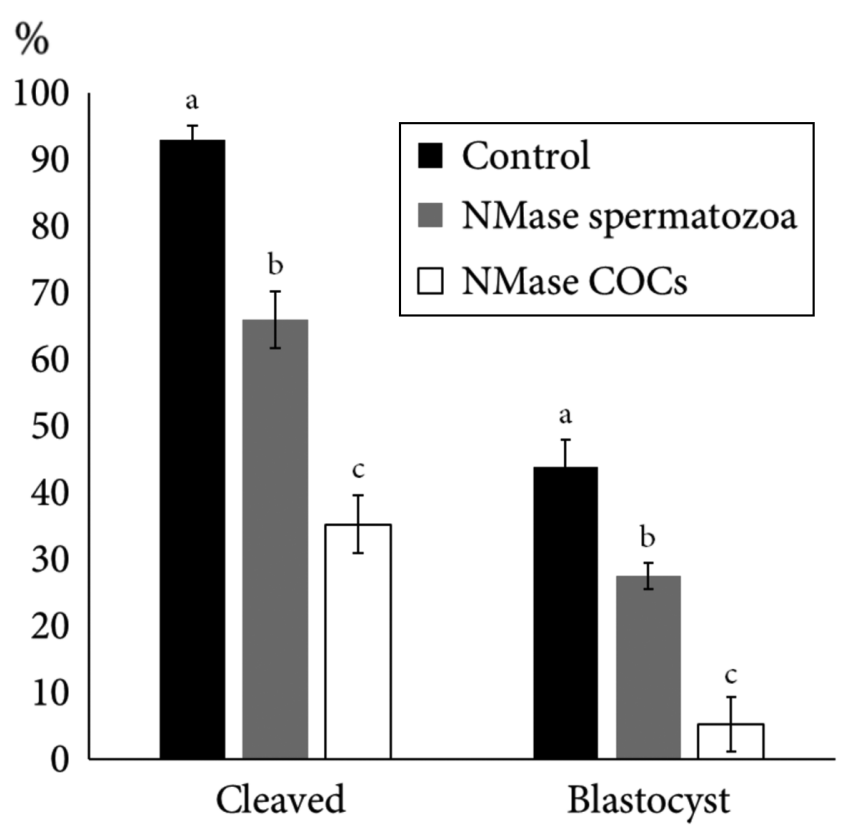

Figure 3 Percentage of cleaved zygotes observed on Day 2 (Day $0=$ day of fertilization) and blastocysts on Day 8 after treatment of cumulus-oocyte complexes (COCs) or sperm with neuraminidase (NMase; $n=50$ COCs per treatment, $n=3$ replicates). Untreated COCs fertilized with untreated sperm were used as control. Data reported as least-squares mean \pm S.E.M. Different superscripts between treatment groups within cleavage or blastocyst rate indicate a difference $(P<0.001)$. Experiment 2 .

In order to determine whether the results observed in the sperm treatment group were really due to a removal of sialic acid from these cells, rather than a carryover effect of NMase on the oocytes, sperm or oocytes were incubated for 1 or $5 \mathrm{~h}$ in the presence of the enzyme. As expected, increasing COC incubation with NMase to $5 \mathrm{~h}$ lowered cleavage rate from $75 \pm 4 \%$ in the control to $9 \pm 2 \%(P<0.001$; Fig. $4 \mathrm{~A})$. This also led to a decrease in blastocyst rate $(1 \pm 0.7 \%$ in the NMase-treated group vs $31 \pm 4 \%$ in the control group; $P<0.01)$. The same tendency was observed when time of incubation of sperm with NMase was increased. In this case, cleavage rate decreased to $44 \pm 4 \%$ from the $81 \pm 3 \%$ observed in the 5 -h control group $(P<0.05$; Fig. 4B). Blastocyst rate decreased from $43 \pm 4 \%$, in the control group, to $13 \pm 3 \%$ when sperm were treated with NMase for $5 \mathrm{~h}$.

Treating sperm with NMase for $5 \mathrm{~h}$ increased their ability to bind to the ZP. This was evidenced by a higher average number of NMase-treated sperm found on the ZP in comparison with the control group $(17 \pm 3.0$ vs $8 \pm 2.0$, respectively; $P<0.05$; Fig. $5 A$ ). Surprisingly, although no differences were observed in overall penetration rate when both monospermic and polyspermic fertilization were taken into account, a higher rate of polyspermic penetration was observed in the NMase group when compared to the control $(12 \%$ vs $2 \%$, respectively; $P<0.05$; Fig. 5B and C).
A $\%$

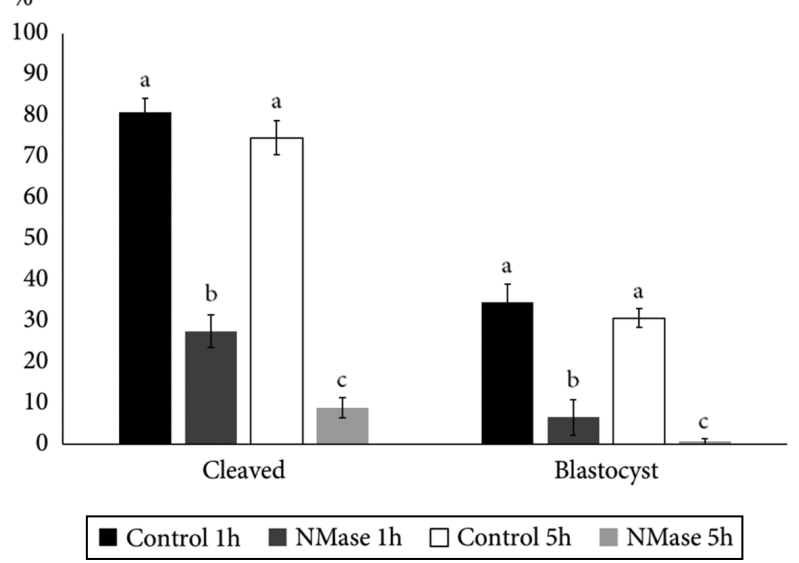

B \%

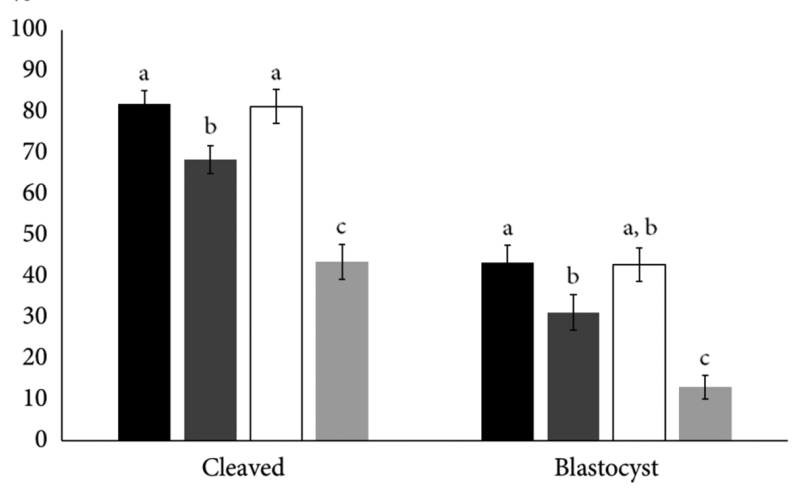

口 Control 1h $\square$ NMase $1 \mathrm{~h} \quad \square$ Control 5h $\square$ NMase 5h

Figure 4 (A) Percentage of cleaved zygotes observed on Day 2 (Day $0=$ day of fertilization) and blastocysts on Day 8 after treatment of cumulus-oocyte complexes (COCs) for 1 or $5 \mathrm{~h}$ with neuraminidase (NMase; $n=50$ COCs per treatment, 3 replicates). Untreated COCs were used as control. Data reported as means \pm S.E.M. Different superscripts between treatment groups within cleavage or blastocyst rate indicate a difference $(P<0.001)$. (B) Cleavage and blastocyst rate after incubation of sperm for 1 or $5 \mathrm{~h}$ in the presence of NMase. COCs fertilized with untreated sperm were used as controls. Data reported as least-squares means \pm S.E.M. Different superscripts between treatment groups within cleavage or blastocyst rate indicate a difference $(P<0.01)$. Experiment 2 .

\section{Experiment 3: Effect of NMase treatment on sperm motility, capacitation and acrosome reaction}

In order to determine whether the results observed in the mucus penetration and IVF experiments were due to an effect of NMase treatment on sperm motility, CASA was performed (Table 1). As expected, motility and progressive motility dramatically decreased from the 1-h to the 5-h incubation time points in both NM treatment (overall motility: $62 \pm 4.8 \%$ vs $14 \pm 4.6 \%$; progressive motility: $57 \pm 4.3 \%$ vs $12 \pm 4.3 \% ; P<0.001)$ and control (overall motility: $78 \pm 4.6 \%$ vs $21 \pm 4.6 \%$; progressive motility: $72 \pm 4.3 \%$ vs $18 \pm 4.3 \%: P<0.001)$ groups. 

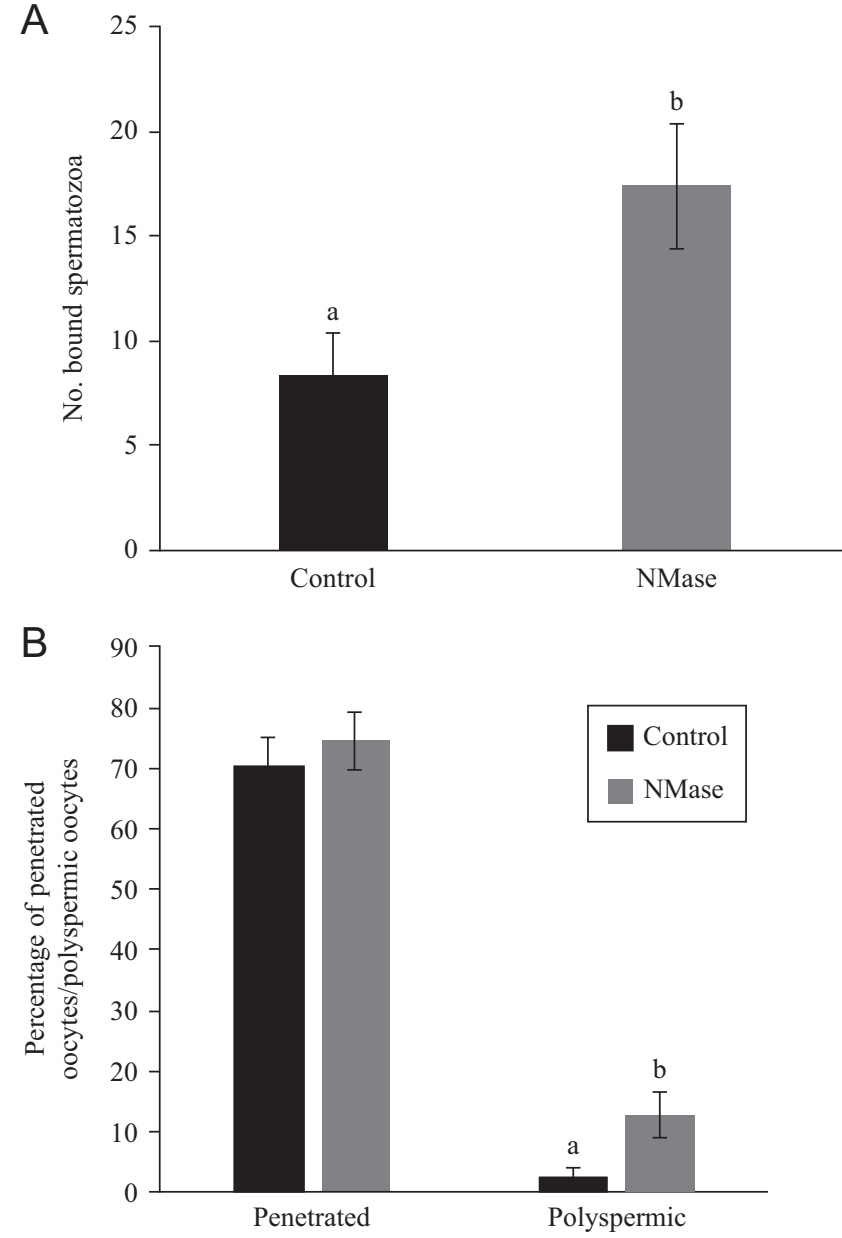

C

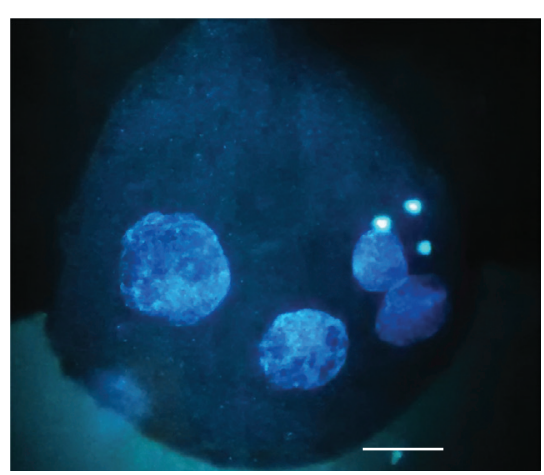

Figure 5 (A) Average number of sperm bound to the ZP after treatment with neuraminidase (NMase). (B) Overall penetration, and polyspermy rates in cumulus-oocyte complexes (COCs) fertilized with treated sperm. (C) Representative image of a polyspermic fertilization found in the NMase treatment group where 4 pronuclei are clearly visible in an oocyte. Bar represents $40 \mu \mathrm{m}$. Different superscripts between treatment groups indicate a difference $(P<0.01)$. Data reported as least-squares means \pm S.E.M. Experiment 2.

Incubation of sperm with NMase for $1 \mathrm{~h}$ decreased both overall motility and progressive motility in comparison with the untreated control $(62 \pm 4.8 \%$ vs $78 \pm 4.6 \%$ and $57 \pm 4.3 \%$ vs $72 \pm 4.3 \%$, respectively: $P<0.001)$. After $5 \mathrm{~h}$ of incubation, overall motility of NMase-treated sperm did not differ from control sperm, but the percentage of progressive cells was lower $(12 \pm 4.3 \%$ vs $18 \pm 4.3 \%$ : $P<0.001)$. Incubation with NMase had no effect on the additional motion parameters studied (VCL, VSL, VAP, LIN, ALH, DAP, DCL and DSL), except for a higher rate of WOB and higher BCF observed in this group after $5 \mathrm{~h}$ of incubation in comparison with the control $(66 \pm 2.9 \%$ vs $63 \pm 2.9 \%$ and $37 \pm 1.9$ vs $33 \pm 1.9 \mathrm{~Hz}$, respectively; $P<0.05)$.

Flow cytometric analysis was performed in NMasetreated and control sperm to determine their ability to undergo capacitation and the acrosome reaction. Samples were labelled with MC, PNA and YP. Nonviable sperm exhibited YP staining and were excluded from the analysis by gating them out. The analysis of the data was performed in single viable sperm as described in Supplementary Fig. 1.

The highest percentages of MC-labelled sperm in both control and NM treatment were observed at T1. Supplementation of the media with $\mathrm{Ca}^{2+}$ ionophore did not increase the percentage of capacitated sperm (Table 2). In addition, no differences were observed in MC-labelling between control and NMase-treated sperm at any of the time points studied $(P>0.05)$.

When PNA labelling was analysed, three population of sperm could be observed from T3 which we referred to as 'low', 'medium' and 'high' PNA-labelled sperm. Medium and high PNA-labelled sperm were considered acrosome-reacted. As expected, the percentage of PNA-labelled cells, as well as fluorescence intensity, increased over time (Table 2). As expected, the presence of $\mathrm{Ca}^{2+}$ ionophore induced an increase in the percentage of acrosome-reacted sperm from T1 onwards, reaching the highest value at T3 (Table 2). Again, no differences were observed between treatments.

\section{Experiment 4: Role of sperm Siglecs in sperm-oocyte interaction}

Because bull sperm express Siglecs on the anterior head and neck region (Alkhodair et al. 2018), we hypothesized that interaction with the oocyte Sia is mediated by sperm Siglecs. However, 1-h incubation of sperm with anti-Siglec-2, $-5,-6,-10$ or $-5 / 14$ antibodies had no effect on their ability to fertilize in-vitro-matured oocytes (Table 3).

\section{Discussion}

The main findings of this study were: (1) Incubation of sperm in fertilization media led to a progressive loss of Sia which was more dramatic when NMase was added to the media. (2) Treatment of sperm with NMase led to a reduced mucus penetration ability, as well as a decrease in overall and progressive motility. (3) Removal of Sia from the COCs or sperm using NMase 
Table 1 Motility parameters assessed in sperm incubated for $1 \mathrm{~h}$ or $5 \mathrm{~h}$ in the presence or absence of NMase.

\begin{tabular}{|c|c|c|c|c|}
\hline & Control $1 \mathrm{~h}$ & NMase $1 \mathrm{~h}$ & Control $5 \mathrm{~h}$ & NMase $5 \mathrm{~h}$ \\
\hline Motility (\%) & $78 \pm 4.6^{\mathrm{a}}$ & $62 \pm 4.8^{\mathrm{b}}$ & $21 \pm 4.6^{c}$ & $14 \pm 4.6^{c}$ \\
\hline Progressive motility (\%) & $72 \pm 4.3^{\mathrm{a}}$ & $57 \pm 4.3^{b}$ & $18 \pm 4.3^{c}$ & $12 \pm 4.3^{d}$ \\
\hline $\mathrm{VCL}$ & $183 \pm 8.4^{\mathrm{a}}$ & $193 \pm 8.8^{\mathrm{a}}$ & $150 \pm 8.4^{b}$ & $143 \pm 8.4^{b}$ \\
\hline VSL & $91 \pm 9.51^{\mathrm{a}, \mathrm{c}}$ & $100 \pm 9.7^{c}$ & $87 \pm 9.7^{a, b}$ & $90 \pm 9.5^{a, b}$ \\
\hline VAP & $104 \pm 8.7^{\mathrm{a}, \mathrm{c}}$ & $112 \pm 8.9^{\mathrm{a}}$ & $92 \pm 8.7^{b}$ & $96 \pm 8.7^{b, c}$ \\
\hline LIN (\%) & $49 \pm 3.5^{\mathrm{a}}$ & $51 \pm 3.6^{\mathrm{a}}$ & $58 \pm 3.5^{b}$ & $62 \pm 3.5^{b}$ \\
\hline ALH & $8 \pm 0.3^{\mathrm{a}}$ & $8 \pm 0.3^{\mathrm{a}}$ & $6 \pm 0.3^{b}$ & $5 \pm 0.3^{b}$ \\
\hline DAP & $46 \pm 3.9$ & $51 \pm 4.1$ & $42 \pm 3.9$ & $44 \pm 3.9$ \\
\hline DCL & $82 \pm 4.3^{\mathrm{a}}$ & $88 \pm 4.6^{a}$ & $67 \pm 4.3^{b}$ & $63 \pm 4.3^{b}$ \\
\hline DSL & $50 \pm 3.2^{\mathrm{a}}$ & $44 \pm 3.7^{\mathrm{a}, \mathrm{b}, \mathrm{c}}$ & $38 \pm 3.2^{\mathrm{b}}$ & $41 \pm 3.2^{b, c}$ \\
\hline WOB (\%) & $57 \pm 2.9^{\mathrm{a}}$ & $57 \pm 2.9^{\mathrm{a}}$ & $63 \pm 2.9^{b}$ & $66 \pm 2.9^{c}$ \\
\hline $\mathrm{BCF}$ & $28 \pm 1.9^{\mathrm{a}}$ & $31 \pm 2^{\mathrm{a}}$ & $33 \pm 1.9^{b}$ & $37 \pm 1.9^{c}$ \\
\hline
\end{tabular}

Data reported as least-square means \pm S.E.M. Different superscripts between treatment groups indicate a difference $(P<0.01)$. Experiment 3 . $\mathrm{ALH}$, amplitude of lateral head displacement; BCF, beat cross frequency; DAP, distance average path; DCL, distance curved line; DSL, distance straight line; LIN, linearity; VAP, velocity average path; VCL, curvilinear velocity; VSL, velocity straight line; WOB, wobble.

had a negative effect on fertilization rate and subsequent embryo development. (4) Incubation of sperm with antiSiglec-2, -5, -6, -10 or $-5 / 14$ antibodies had no effect on their ability to fertilize in-vitro-matured oocytes. (5) Treatment of sperm with NMase led to an increased ability to bind to the $\mathrm{ZP}$, and an increased rate of polyspermic fertilization.

The primary biological role of sperm is to transmit the paternal genetic message encoded in the DNA to the next generation. In order to fulfil this goal, the male gamete must be able to transverse the mucus-lined female reproductive tract, evade the immune surveillance of the female, interact with the cumulus cells and selectively bind the ZP and the plasma membrane of the oocyte. A growing body of evidence links glycans and glycanbinding molecules to most of these sperm functional roles (Yudin et al. 2005, Tollner et al. 2008a,b, Kadirvel et al. 2012, Roy et al. 2014, Ma et al. 2016). Changes in the sperm glycome occur due to proteolysis, shedding or incorporation of glycoproteins that takes place during the epididymal transit (Toshimori et al. 1988, 1991, Tollner et al. 2008a,b, Yudin et al. 2005, Villaverde

Table 2 Percentage of merocyanine 540 (MC) and Alexa Fluor 647-conjugated-peanut agglutinin (PNA) labelled control and NMase-treated bull sperm.

\begin{tabular}{|c|c|c|c|c|c|}
\hline Antibody dilution & Oocytes fertilized $(n)$ & $\begin{array}{l}\text { \% Cleavage rate } \\
(\text { mean } \pm \text { S.E.M. })\end{array}$ & $\begin{array}{c}n \text { cleaved } / n \text { oocytes } \\
\text { fertilized }\end{array}$ & $\begin{array}{l}\text { \% Blastocyst rate } \\
(\text { mean } \pm \text { S.E.M. })\end{array}$ & $\begin{array}{c}n \text { blastocyst } / n \text { oocytes } \\
\text { fertilized }\end{array}$ \\
\hline \multicolumn{6}{|l|}{ Siglec-2 } \\
\hline $1: 50$ & 142 & $85 \pm 4.1$ & $118 / 142$ & $32 \pm 6.4$ & $45 / 142$ \\
\hline $1: 20$ & 132 & $75 \pm 3.9$ & $99 / 132$ & $35 \pm 4.9$ & $46 / 132$ \\
\hline \multicolumn{6}{|l|}{$\lg G$} \\
\hline $1: 20$ & 143 & $81 \pm 3.7$ & $116 / 143$ & $40 \pm 2.0$ & $57 / 143$ \\
\hline \multicolumn{6}{|l|}{ Siglec-5 } \\
\hline $1: 50$ & 113 & $82 \pm 2.6$ & $93 / 113$ & $40 \pm 3.9$ & $45 / 113$ \\
\hline $1: 20$ & 111 & $84 \pm 6.3$ & $93 / 111$ & $50 \pm 6.1$ & $55 / 111$ \\
\hline \multicolumn{6}{|l|}{$\lg \mathrm{G}$} \\
\hline $1: 20$ & 107 & $72 \pm 5.3$ & $77 / 107$ & $36 \pm 3.5$ & $39 / 107$ \\
\hline \multicolumn{6}{|l|}{ Siglec-6 } \\
\hline $1: 50$ & 116 & $75 \pm 7.9$ & $87 / 116$ & $29 \pm 16.3$ & $34 / 116$ \\
\hline $1: 20$ & 111 & $77 \pm 6.2$ & $85 / 111$ & $23 \pm 5.1$ & $25 / 111$ \\
\hline \multicolumn{6}{|l|}{$\lg G$} \\
\hline $1: 20$ & 109 & $67 \pm 5.8$ & $73 / 109$ & $19 \pm 8.5$ & $21 / 109$ \\
\hline \multicolumn{6}{|l|}{ Siglec-10 } \\
\hline $1: 50$ & 130 & $71 \pm 11.6$ & $92 / 130$ & $33 \pm 7.4$ & $43 / 130$ \\
\hline $1: 20$ & 127 & $77 \pm 6.7$ & $98 / 127$ & $28 \pm 7.3$ & $35 / 127$ \\
\hline \multicolumn{6}{|l|}{$\mathrm{lgG}$} \\
\hline $1: 20$ & 125 & $66 \pm 5.7$ & $83 / 125$ & $11 \pm 7.5$ & $14 / 125$ \\
\hline \multicolumn{6}{|l|}{ Siglec-5/14 } \\
\hline 1:50 & 131 & $84 \pm 2.7$ & $110 / 131$ & $37 \pm 7.4$ & $48 / 131$ \\
\hline $1: 20$ & 120 & $73 \pm 7.5$ & $88 / 120$ & $38 \pm 6.9$ & $45 / 120$ \\
\hline \multicolumn{6}{|l|}{$\lg G$} \\
\hline $1: 20$ & 130 & $74 \pm 6.3$ & $96 / 130$ & $25 \pm 10.1$ & $32 / 130$ \\
\hline
\end{tabular}

Both treatments were incubated in the presence (activated) or absence (non-activated) of $\mathrm{Ca}^{2+}$ ionophore. Data reported as least-squares means \pm S.E.M. Experiment 3 . 
Table 3 Effect of incubation of bull sperm with different Siglec antibodies on cleavage and blastocyst rate.

\begin{tabular}{|c|c|c|c|c|c|c|c|c|c|c|}
\hline \multirow[b]{3}{*}{ Treatment } & & & \multicolumn{8}{|c|}{$\%$ High and Medium PNA labelled sperm } \\
\hline & \multicolumn{2}{|c|}{$\%$ MC labelled sperm (T1) } & \multicolumn{4}{|c|}{ Activated } & \multicolumn{4}{|c|}{ Non-activated } \\
\hline & Activated & Non-activated & T0 & $\mathrm{T} 1$ & T3 & T5 & T0 & T1 & $\mathrm{T} 3$ & T5 \\
\hline Control & $56 \pm 4.0$ & $55 \pm 4.1$ & $0.2 \pm 5.2$ & $36 \pm 6.5$ & $50 \pm 5.2$ & $46 \pm 5.2$ & $0.1 \pm 5.24$ & $2 \pm 6.5$ & $3 \pm 5.2$ & $5 \pm 5.2$ \\
\hline NMase & $49 \pm 4.0$ & $38 \pm 5.0$ & $0.2 \pm 5.2$ & $36 \pm 6.5$ & $50 \pm 5.2$ & $55 \pm 5.2$ & $0.2 \pm 5.24$ & $2 \pm 6.5$ & $4 \pm 5.2$ & $7 \pm 5.2$ \\
\hline
\end{tabular}

Sperm incubated with IgG prior to fertilization were used as control in all cases. Experiment 4.

et al. 2016). In addition, glycan-modifying enzymes (such as glycosyltransferases and glycohydrolases) in the epididymal fluid also induce rearrangement of glycan moieties at this time (Nicolson et al. 1977, Tulsiani et al. 1995a,b, Ma et al. 2012, Pini et al. 2017). As a result, at the time of ejaculation, the surface of sperm is composed of $40 \%$ Sia, 30\% fucose and $27 \%$ hexosamines (Calzada et al. 1994). Interestingly, this surface glycome can also be altered following cryopreservation techniques (Pini et al. 2017).

In order to study the role of Sia on sperm function and gamete interaction, sperm or oocytes were incubated in the presence of $0.1 \mathrm{UN} / \mathrm{mL}$ NMase from C. perfringens type $\mathrm{V}$, an enzyme that cleaves terminal sialic acid residues which are $\alpha-2,3-, \alpha-2,6$ - or $\alpha-2,8$-linked to Gal, GlcNac, GalNAc, AcNeu, GlcNeu, oligosaccharides, glycolipids or glycoproteins. Although it affects all linkages, this type of NMase is most efficient against $\alpha$ 2,3 linked Sia. It can be argued that the results reported in this study can be due to the presence of NMase enzyme in the fertilization media rather than to the activity of the enzyme cleaving terminal Sia. However, the percentage of WGA-positive cells was reduced in half in the NMase group in comparison with the control at $1 \mathrm{~h}$, and was more than 3 times lower at $5 \mathrm{~h}$ of incubation. This indicates a NMase-dependent loss of Sia, which is in agreement with the work of Velásquez et al. (2007). Velásquez et al. used NMase under the same conditions that were used in this study, and were able to block its effect by using an inhibitor, which would suggest that the results observed were due to the action of the enzyme as well.

Treatment of sperm with NMase for $1 \mathrm{~h}$ had no effect on the ability of sperm to migrate through CM collected from cows in oestrus. This was surprising, as this treatment induced a decrease in overall and progressive motility in comparison with the control. However, increasing the time of incubation to $5 \mathrm{~h}$ reduced the ability of NMase-treated sperm to migrate through this matrix. Similar results have been observed in primates, where treatment with NMase or removal of the highly sialylated DEFB126 protein affected mucus penetration ability (Tollner et al. 2008a). In our study, incubation of sperm with NMase for $5 \mathrm{~h}$ decreased the rate of progressive motility, which could help explain the results observed in the mucus penetration assay. In addition, it has been proposed that Sia confers sperm with an electronegative surface charge that facilitates migration through mucus by minimizing the interaction of sperm with the negatively charged CM (Tollner et al. 2012). The importance of Sia in this particular sperm characteristic is highlighted by the fact that men carrying a mutation in the DEFB126 gene are subfertile due apparently to a reduced ability of their sperm to penetrate CM (Tollner et al. 2011).

Sia have also been implicated in the recognition and binding of the ZP by sperm (Velásquez et al. 2007, Pang et al. 2011). In the present study, exposing oocytes to NMase led to a decrease in both cleavage and blastocyst rate in comparison with untreated control oocytes. Increasing time of incubation with NMase from $1 \mathrm{~h}$ to $5 \mathrm{~h}$ had a more dramatic effect, as evidenced by a drop of 65 percentage points in cleavage in comparison with the control group. This supports the theory that oocyte Sia are required for sperm-ZP interaction in the bovine. Velásquez et al. (2007) reported that a $\alpha-2,3$ linked Sia is required for ZP binding in this species. In their study, selective cleavage by specific sialidases or selective blockage of this site by specific lectins led to a decrease in the number of sperm bound to the ZP (Velásquez et al. 2007). The results presented in this study take this one step further and show that, as expected, fertilization and embryo development rates decrease by removing these Sia from the oocyte. The sperm receptor that binds to this oocyte Sia remains unknown. However, a recent study has characterized Siglecs-2, -5, -6, -10 and -14 on the sperm surface (Alkhodair et al. 2018). Siglecs-6 and -10 are particularly interesting with regard to our study as they are present on the anterior head of sperm (Alkhodair et al. 2018), making them susceptible to interact with the female gamete. In addition, Siglec-10 was found to be differentially expressed in sperm from bulls with a high fertility index (Lalancette et al. 2008). Thus, anti-Siglec-2, $-5,-6,-10$ and $-5 / 14$ were added to sperm before fertilization in an attempt to block sperm-oocyte interaction. However, no differences were observed between any of these treatments and the control, indicating that these Siglecs are not directly involved in oocyte recognition.

During capacitation, mouse sperm release sialidases that lead to the loss of $20 \%$ of the sperm sialome (Ma et al. 2012). Removal of sperm Sia is probably also aided by sialidases in the oocyte and in the female reproductive tract (Ganguly et al. 1976, Velásquez et al. 
2007). The importance of this event is highlighted by the fact that men who lack one of the two sperm sialidases exhibit subfertility (Ma et al. 2012). However, this also means that $80 \%$ of the sperm Sia content remains intact in the surface. This led us to hypothesize that sperm Sia might also be involved with the recognition of the oocyte vestments. Subjecting sperm to the same NMase treatment as that used on the oocytes resulted in a decrease in cleavage and blastocyst rates, albeit not as dramatic as when oocytes were exposed to this enzyme. A 5-h incubation of sperm with NMase decreased cleavage rate by $38 \%$ and blastocyst rate by $30 \%$. To further investigate these observations, oocytes fertilized with NMase-treated sperm were fixed at $3 \mathrm{~h}$ and $17 \mathrm{~h}$ post fertilization which allowed us to study sperm-ZP binding and penetration. Surprisingly, treatment with NMase increased the ability of sperm to bind to the ZP. This is consistent with observations in humans, where treatment of sperm with NMase from $A$. ureafaciens led to a dose-dependent enhancement of sperm attachment to the ZP (Lassalle \& Testart 1994). In addition, a recent study has also shown that biantennary complex types $\mathrm{N}$-glycans terminating with $\alpha 2,6$ sialic acids are lower in sperm recovered from buffalos during the breeding season than during the non-breeding season (Accogli et al. 2017). However, the increase in sperm-ZP binding made it difficult to explain the decrease in cleavage rate observed in the in vitro fertility experiments in this study. When sperm penetration and polyspermic rate were assessed $17 \mathrm{~h}$ post fertilization, a higher rate of polyspermic penetration was observed in the NMase group when compared to the control. This higher rate of abnormal fertilization could explain in part the decreased cleavage rate observed in the initial experiments.

Sperm capacitation refers to the set of physiological changes that confer on sperm the ability to fertilize the oocyte (Yanagimachi 1994). These changes include hyperactivation of flagellar motility, regulation of signal transduction pathways that allow a response to chemoattractants, and expression of the ability to acrosome react and to interact with the oocyte (Florman \& Fissore 2014). This process takes place in the female reproductive tract but does not occur at the same time in the whole sperm population (Buffone et al. 2012). The oviduct appears to regulate sperm capacitation to avoid over-capacitation and premature acrosome reaction, ensuring a constant supply of fertile sperm to the site of fertilization (Boilard et al. 2002, Fazeli et al. 2003). Treatment with NMase had no effect either on different motility parameters that have been correlated with hyperactivation (VCL, VSL, LIN, VAP, ALH, DAP, DCL, and DSL; Cancel et al. 2000), or in M540 labelling, a marker that has been correlated with early-capacitationdependent changes in membrane fluidity (Harrison et al. 1996, Rathi et al. 2001). In addition, no differences were observed in the ability of sperm to acrosome react, as evidenced by the same percentage of PNA-labelled sperm in both NMase and control groups observed over time. This would suggest that the sialidaseinduced increase in sperm-ZP binding is independent of capacitation or acrosomal status.

Sialidases secreted by the sperm during capacitation, as well as sialidases present in the oviduct, remove sperm surface Sia, which probably uncovers underlying molecules that can interact with the ZP. Indeed, in Experiment 1, a progressive loss of Sia was observed in sperm incubated in fertilization media, but control sperm presented more Sia on their surface than NMase-treated sperm. Thus, treatment of the whole sperm population with NMase would synchronize the acquisition of oocyte-binding ability, increasing the number of sperm binding to the ZP and, therefore, increasing the chances of polyspermy. This higher polyspermic rate likely alters early embryo development, which results in low cleavage and blastocyst rates. The results presented in this study, together with the literature available, suggest that sperm require Sia to reach the fertilization site but, once there, they need to be removed in order for bovine sperm to interact, bind and fertilize the oocyte. However, fine regulation of this process is required to avoid abnormal fertilization and embryo development.

\section{Supplementary data}

This is linked to the online version of the paper at https://doi.org/10.1530/REP-17-0429.

\section{Declaration of interest}

The authors declare that there is no conflict of interest that could be perceived as prejudicing the impartiality of the research reported.

\section{Funding}

This work was supported by a grant from the Irish Department of Agriculture, Food and the Marine under the Research Stimulus Programme (Grant No. 11/S/104).

\section{Acknowledgements}

The authors wish to thank Mary Wade for her technical assistance.

\section{References}

Accogli G, Lacalandra GM, Aiudi G, Cox SN \& Desantis S 2017 Differential surface glycoprofile of buffalo bull spermatozoa during mating and non-mating periods. Animal 11 1807-1815. (https://doi.org/10.1017/ S1751731117000453) 
Alkhodair K, Almhanna H, McGetrick J, Gedair S, Gallagher ME, Fernandez-Fuertes B, Tharmalingam T, Larsen PB, Fitzpatrick, E, Lonergan P2018 Siglec expression on the surface of human, bull and ram sperm. Reproduction 155 361-371. (https://10.1530/REP-170475)

Amaral A, Castillo J, Ramalho-Santos J \& Oliva R 2014 The combined human sperm proteome: cellular pathways and implications for basic and clinical science. Human Reproduction Update 20 40-62. (https:// doi.org/10.1093/humupd/dmt046)

Boilard M, Bailey J, Collin S, Dufour M \& Sirard M-A 2002 Effect of bovine oviduct epithelial cell apical plasma membranes on sperm function assessed by a novel flow cytometric approach. Biology of Reproduction 67 1125-1132. (https://doi.org/10.1095/biolreprod67.4.1125)

Buffone MG, ljiri TW, Cao W, Merdiushev T, Aghajanian HK \& Gerton GL 2012 Heads or tails? Structural events and molecular mechanisms that promote mammalian sperm acrosomal exocytosis and motility. Molecular Reproduction and Development 79 4-18. (https://doi. org/10.1002/mrd.21393)

Calzada L, Salazar EL \& Pedrón N 1994 Presence and chemical composition of glycoproteic layer on human spermatozoa. Archives of Andrology 33 87-92. (https://doi.org/10.3109/01485019408987808)

Cancel AM, Lobdell D, Mendola P \& Perreault SD 2000 Objective evaluation of hyperactivated motility in rat spermatozoa using computerassisted sperm analysis. Human Reproduction 15 1322-1328. (https:// doi.org/10.1093/humrep/15.6.1322)

Crocker PR, Paulson JC \& Varki A 2007 Siglecs and their roles in the immune system. Nature Reviews Immunology 7 255-266. (https://doi. org/10.1038/nri2056)

Fazeli A, Elliott RM, Duncan AE, Moore A, Watson PF \& Holt WV 2003 In vitro maintenance of boar sperm viability by a soluble fraction obtained from oviductal apical plasma membrane preparations. Reproduction 125 509-517. (https://doi.org/10.1530/rep.0.1250509)

Flesch FM, Voorhout WF, Colenbrander B, van Golde LMG \& Gadella BM 1998 Use of lectins to characterize plasma membrane preparations from boar spermatozoa: a novel technique for monitoring membrane purity and quantity. Biology of Reproduction 59 1530-1539. (https://doi. org/10.1095/biolreprod59.6.1530)

Florman HM \& Fissore RA 2014 Fertilization in mammals. In Knobil and Neill's Physiology of Reproduction, pp 149-196. Academic Press: Cambridge, MA, USA.

Ganguly S, Sarkar D \& Ghosh JJ 1976 Sialic acid and sialidase activity in human endometrial tissue, uterine fluid and plasma under different conditions of uterine dysfunction. Acta Endocrinologica 81 574-579. (https://doi.org/10.1530/acta.0.0810574)

Harrison RA, Ashworth PJ \& Miller NG 1996 Bicarbonate/CO2, an effector of capacitation, induces a rapid and reversible change in the lipid architecture of boar sperm plasma membranes. Molecular Reproduction and Development 45 378-391. (https://doi.org/10.1002/(SICl)10982795(199611)45:3<378::AID-MRD16>3.0.CO;2-V)

Kadirvel G, Machado SA, Korneli C, Collins E, Miller P, Bess KN, Aoki K, Tiemeyer M, Bovin N \& Miller DJ 2012 Porcine sperm bind to specific 6-sialylated biantennary glycans to form the oviduct reservoir. Biology of Reproduction 87 147. (https://doi.org/10.1093/biolreprod/87. s1.147)

Kiernan M, Fahey AG \& Fair S 2013 The effect of the in vitro supplementation of exogenous long-chain fatty acids on bovine sperm cell function. Reproduction, Fertility, and Development 25 947-954. (https://doi. org/10.1071/RD12204)

Kraemer PM 1966 Sialic acid of mammalian cell lines. Journal of Cellular Physiology 67 23-34. (https://doi.org/10.1002/jcp.1040670104)

Lalancette C, Thibault C, Bachand I, Caron N \& Bissonnette N 2008 Transcriptome analysis of bull semen with extreme nonreturn rate: use of suppression-subtractive hybridization to identify functional markers for fertility. Biology of Reproduction 78 618-635. (https://doi.org/10.1095/ biolreprod.106.059030)

Lassalle B \& Testart J 1994 Human zona pellucida recognition associated with removal of sialic acid from human sperm surface. Journal of Reproduction and Fertility 101 703-711. (https://doi.org/10.1530/ jrf.0.1010703)

Ma F, Wu D, Deng L, Secrest P, Zhao J, Varki N, Lindheim S \& Gagneux P 2012 Sialidases on mammalian sperm mediate deciduous sialylation during capacitation. Journal of Biological Chemistry 287 38073-38079. (https://doi.org/10.1074/jbc.M112.380584)

Ma X, Pan Q, Feng Y, Ma Q, Gagneux P \& Ma F 2016 Sialylation facilitates the maturation of mammalian sperm and affects its survival in female uterus. Biology of Reproduction 94 123. (https://doi.org/10.1095/ biolreprod.115.137810)

Macauley MS, Crocker PR \& Paulson JC 2014 Siglec-mediated regulation of immune cell function in disease. Nature Reviews Immunology $\mathbf{1 4}$ 653-666. (https://doi.org/10.1038/nri3737)

Monsigny M, Roche AC, Sene C, Maget-Dana R \& Delmotte F 1980 Sugar-lectin interactions: how does wheat-germ agglutinin bind sialoglycoconjugates? European Journal of Biochemistry 104 147-153. (https://doi.org/10.1111/j.1432-1033.1980.tb04410.x)

Nicolson GL, Usui N, Yanagimachi R, Yanagimachi H \& Smith JR 1977 Lectin-binding sites on the plasma membranes of rabbit spermatozoa. Changes in surface receptors during epididymal maturation and after ejaculation. Journal of Cell Biology 74 950-962. (https://doi.org/10.1083/ jcb.74.3.950)

Pang P-C, Chiu PCN, Lee C-L, Chang L-Y, Panico M, Morris HR, Haslam SM, Khoo K-H, Clark GF, Yeung WSB et al. 2011 Human sperm binding is mediated by the sialyl-Lewis(x) oligosaccharide on the zona pellucida. Science 333 1761-1764. (https://doi.org/10.1126/science.1207438)

Peddinti D, Nanduri B, Kaya A, Feugang JM, Burgess SC \& Memili E 2008 Comprehensive proteomic analysis of bovine spermatozoa of varying fertility rates and identification of biomarkers associated with fertility. BMC Systems Biology 2 19. (https://doi.org/10.1186/17520509-2-19)

Pini T, Leahy T \& Paul de Graaf S 2017 Seminal plasma and cryopreservation alter ram sperm surface carbohydrates and interactions with neutrophils. Reproduction, Fertility, and Development Epub. (https://doi.org/10.1071/ RD17251)

Rathi R, Colenbrander B, Bevers MM \& Gadella BM 2001 Evaluation of in vitro capacitation of stallion spermatozoa. Biology of Reproduction $\mathbf{6 5}$ 462-470. (https://doi.org/10.1095/biolreprod65.2.462)

Roy D, Dey S, Majumder GC \& Bhattacharyya D 2014 Occurrence of novel $\mathrm{Cu}^{2+}$-dependent sialic acid-specific lectin, on the outer surface of mature caprine spermatozoa. Glycoconjugate Journal 31 281-288. (https://doi.org/10.1007/s10719-014-9524-z)

Tecle E \& Gagneux P 2015 Sugar-coated sperm: unraveling the functions of the mammalian sperm glycocalyx. Molecular Reproduction and Development 82 635-650. (https://doi.org/10.1002/mrd.22500)

Tollner TL, Yudin AI, Treece CA, Overstreet JW \& Cherr GN 2008a Macaque sperm coating protein DEFB126 facilitates sperm penetration of cervical mucus. Human Reproduction 23 2523-2534. (https://doi. org/10.1093/humrep/den276)

Tollner TL, Yudin AI, Tarantal AF, Treece CA, Overstreet JW \& Cherr GN $2008 b$ Beta-defensin 126 on the surface of macaque sperm mediates attachment of sperm to oviductal epithelia. Biology of Reproduction $\mathbf{7 8}$ 400-412. (https://doi.org/10.1095/biolreprod.107.064071)

Tollner TL, Venners SA, Hollox EJ, Yudin AI, Liu X, Tang G, Xing H, Kays RJ, Lau T, Overstreet JW et al. 2011 A common mutation in DEFB126 causes impaired sperm function and subfertility. Science Translational Medicine 3 92ra65. (https://doi.org/10.1126/ scitranslmed.3002289)

Tollner TL, Bevins CL \& Cherr GN 2012 Multifunctional glycoprotein DEFB126 - a curious story of defensin-clad spermatozoa. Nature Reviews Urology 9 365-375. (https://doi.org/10.1038/nrurol.2012.109)

Toshimori K, Araki S \& Ōura C 1988 Masking of sperm maturation antigen by sialic acid in the epididymis of the mouse. Histochemistry $\mathbf{9 0}$ 195-200. (https://doi.org/10.1007/BF00492507)

Toshimori K, Araki S, Oura C \& Eddy EM 1991 Loss of sperm surface sialic acid induces phagocytosis: an assay with a monoclonal antibody T21, which recognizes a 54K sialoglycoprotein. Archives of Andrology 27 79-86. (https://doi.org/10.3109/01485019108987656)

Tulsiani DR, Skudlarek MD, Araki Y \& Orgebin-Crist MC 1995a Purification and characterization of two forms of beta-D-galactosidase from rat epididymal luminal fluid: evidence for their role in the modification of sperm plasma membrane glycoprotein(s). Biochemical Journal 305 41-50. (https://doi.org/10.1042/bj3050041)

Tulsiani DRP, NagDas SK, Skudlarek MD \& Orgebin-Crist M-C 1995b Rat sperm plasma membrane mannosidase: localization and evidence for 
proteolytic processing during epididymal maturation. Developmental Biology 167 584-595. (https://doi.org/10.1006/dbio.1995.1050)

Varki A \& Schauer R 2009 Sialic acids. In Essentials of Glycobiology. Eds A Varki, RD Cummings, JD Esko, HH Freeze, P Stanley, CR Bertozzi, GW Hart \& ME Etzler. Cold Spring Harbor, NY: Cold Spring Harbor Laboratory Press.

Velásquez JG, Canovas S, Barajas $P$, Marcos J, Jiménez-Movilla $M$, Gallego RG, Ballesta J, Avilés M \& Coy P 2007 Role of sialic acid in bovine sperm-zona pellucida binding. Molecular Reproduction and Development 74 617-628.

Villaverde AISB, Hetherington L \& Baker MA 2016 Quantitative glycopeptide changes in rat sperm during epididymal transit. Biology of Reproduction 94 91. (https://doi.org/10.1095/biolreprod.115.134114)

Yanagimachi R 1994 Mammalian fertilization. Physiology of Reproduction 1 189-317.
Yudin AI, Generao SE, Tollner TL, Treece CA, Overstreet JW \& Cherr GN 2005 Beta-defensin 126 on the cell surface protects sperm from immunorecognition and binding of anti-sperm antibodies. Biology of Reproduction 73 1243-1252. (https://doi.org/10.1095/ biolreprod.105.042432)

Received 14 July 2017

First decision 14 August 2017

Revised manuscript received 23 March 2018

Accepted 3 April 2018 